\title{
Automobile usage and urban rail transit expansion: evidence from a natural experiment in Beijing, China
}

\author{
LUNYU XIE \\ School of Economics, Renmin University of China, 617B Mingde Main \\ Building, 59 Zhongguancun Street, Haidian District, Beijing 100872, China. \\ Email:lunyuxie@ruc.edu.cn
}

Submitted 11 August 2015; revised 8 December 2015, 31 December 2015; accepted 6 January 2016; first published online 17 February 2016

\begin{abstract}
Using individual travel diary data collected before and after a rail transit expansion in urban Beijing, the impact of urban rail accessibility improvement on the usage of rail transit, automobiles, buses, walking and bicycling, as well as the cross-area externality induced by congestion alleviation, is estimated. The results show that rail transit usage significantly increased for commuters residing in the affected areas and that the additional rail passengers were previously auto users, rather than bus passengers. The cross-area externality is estimated as small, which implies that the congestion alleviation was not large enough (yet) to change the travel mode choices of commuters residing in areas that did not experience the improvement. Furthermore, the results show that neither the number of commute work trips nor their length increased, indicating that the quantity of travel was not increased by the rail transit expansion.
\end{abstract}

\section{Introduction}

It is well known that automobiles emit harmful pollutants and that exposure to air pollution substantially harms public health. A World Health Organization (WHO) study estimated that urban air pollution accounts for 6.4 million years of life lost annually worldwide (Cohen et al., 2004). Besides air pollution, traffic congestion caused by the wide use of automobiles also has negative effects on public welfare. To reduce the congestion and air pollution caused by automobiles, metropolitan areas worldwide are investing heavily in building or extending urban rail transit systems. Whether congestion and pollution can be reduced through such projects depends on which travel modes commuters reduce when they use more rail transit. This remains an open question in practice.

This study is supported by the Fundamental Research Funds for the Central Universities and the Research Funds of Renmin University of China. 
This study investigates the change in transportation mode usage in Beijing, a megacity unique in the speed of its subway development. With a US\$30bn (200bn Chinese Yuan) investment in building new subway lines, Beijing's subway system grew from a small system with 39 stations in 2002 to more than 300 stations by 2014. The rollout of new subway lines creates a series of contrasts between commuters who experienced rail accessibility improvements and those that did not. In this paper, this rollout is utilized to estimate, ex post, how the completion of new rail transit lines affected the kilometers traveled by rail transit, autos, buses, and walking and bicycling, respectively.

Investment in commuter rail transit is a worldwide phenomenon, driven by a belief in its benefits, including less congestion, less air pollution and improved labor market access for the poor (Kain, 1968; Vickrey, 1969; Chen and Whalley, 2012). Transit authorities believe that the benefit is large; hence, the investment in rail transit is large (Cervero, 1998). For the same reason, passenger fares for public transportation are usually heavily subsidized (Kenworthy and Laube, 2001; Parry and Small, 2009). However, some researchers argue that the cost of building and maintaining new transit is higher than the measured benefit, and point out that the optimistic view of the rail transit benefit was based partially on an overestimation of ridership (Gordon and Willson, 1984; Allport and Thomson, 1990; Kain, 1990, 1992, 1997; Pickrell, 1992).

Besides the unsettled question concerning rail ridership, another equally important question is from which alternative travel modes rail transit riders are diverted. The rail benefit will be higher if rail transit ridership comes at the expense of more polluting modes of transportation such as automobiles, rather than less polluting modes such as bicycles. Besides traffic diversion effects, investments in rail transit may also create traffic by inducing demand for travel (Vickrey, 1969). This study addresses the three questions simultaneously by looking into the changes in distance traveled by various modes and changes in travel quantity.

This paper is the first study to use a (pseudo) panel of individual trips to estimate the ex post effect of rail transit provision on mode usage in the context of a city in the developing world. An estimation of the ex post effect is preferred in terms of causal inference, given the difficulty in predicting the market share of a new rail system by an ex ante study (McFadden et al., 1977; Train, 1978). Discrete choice models, widely used in the travel mode choice literature, ${ }^{1}$ require accurately constructing the attributes of alternatives, especially the alternative specific constants. Inaccurate construction of the alternatives tends to result in inaccurate prediction. In this study, households are observed before and after the coverage changes, taking advantage of three rounds of detailed individual travel diaries in Beijing, with new subway lines completed between the rounds. Households that

1 A partial list of ex ante studies on travel mode by discrete choice models includes Ben-Akiva and Lerman (1974), McFadden (1974), Train (1978, 1980), Ben-Akiva and Morikawa (1990), Hensher and Bradley (1993), Asensio (2002), Alpizar and Carlsson (2003), Hensher and Rose (2007), Liu (2007), and examples discussed in Train (2009). 
are affected and those that are not affected are also observed. This is possible because the rail expansion improved accessibility for the households residing along the new lines, but not for the rest. The main estimation strategy is the differences-in-differences (DID) method. The double differencing removes two types of biases (Imbens and Wooldridge, 2009). One bias comes from the comparison between the treatment group and the control group, which could be the result of permanent differences between these groups. People who prefer rail transit tend to choose to live in areas near rail stations. Cross-sectional studies (Gordon and Willson, 1984; Kain and Liu, 1994; Wardman, 1997; Winston and Shirley, 1998; Petitte, 2001) comparing commuters in nearby areas to those in farther areas usually suffer from this self-selection bias. The other bias comes from the comparison over time, which could be the result of time trends unrelated to the treatment. Macro-economic shocks and transport policies can be the sources of such bias, from which time-series studies (Gaudry, 1975; Greene, 1992; Gomez-Ibanez, 1996) tend to suffer.

To address the cross-area externality, which may dampen the validity of the DID method, the indirect effects of rail expansion are estimated as well. The cross-area externality comes from the fact that the areas without subway expansion can benefit from congestion alleviation when commuters in the affected area travel more by subway and less by automobile. Using rich information on individual trips, a measure of the intensity of spillover from affected areas is constructed. By including the spillover intensity in the regressions, the cross-area externality is estimated and the bias caused by the externality is removed.

This paper also differs from previous literature in the following two ways. First, this paper defines a continuous dependent variable, which is unusual in previous individual data studies. ${ }^{2}$ This continuous definition, the percentage distance traveled by each mode in an individual trip, avoids the arbitrary definition of the main mode when a trip involves more than one mode, which is almost always the case in practice. Secondly, this study takes advantage of the higher frequency of the data - an annual survey as opposed to studies based on decadal census data - to alleviate the selfselection bias caused by migration. Baum-Snow and Kahn (2000) used aggregate data at the census tract level with data points 10 years apart, thus accounting for migration with a predetermined migration rate. While built upon their research design, this paper uses very different data, and the short time frame limits the bias caused by migration. This potential source of endogeneity is tested in a later section.

${ }^{2}$ For aggregate data, the mode usage is measured as the ridership of a transit line or the market share of a mode, which is naturally continuous. For individual data, the natural choice is also continuous, as nearly every transit trip is a mixture of modes. However, standard survey data do not have this detailed information, because in questionnaires it is natural to ask about the modes or the mode combinations a commuter uses, instead of the distance for each mode involved in a trip. Therefore, it is common in the literature to choose discrete models, at the cost of losing information. 
The central result shows that rail transit usage doubled, on average, for commuters who experienced the improvement in rail transit accessibility, compared to the commuters who did not experience such improvement. Auto usage significantly decreased, by 16 per cent, while the impact on bus usage was small and not statistically significant, indicating that the new subway lines in this study diverted auto users instead of bus passengers. The results also show that the spillover effects of subway expansion are not large enough (yet) to affect the travel behavior of commuters residing in the areas without the rail transit accessibility improvement. Furthermore, this paper finds that changes in auto usage and rail transit usage vary with distance to the nearest rail station, traffic infrastructure conditions, and commuters' auto ownership and income. Finally, this paper examines the effect of transit expansion on travel quantity, and finds that neither the number of commute work trips nor their length increased, indicating that little additional travel is induced by the subway expansion.

The remainder of the paper is organized as follows. Section 2 describes the data. Section 3 describes the empirical estimation strategy, presents the results on the effects on distance traveled by various modes, and investigates heterogeneities in the treatment and treatment effects. Section 4 studies the effects on travel quantity. Section 5 concludes.

\section{Data}

This study uses travel diary data from 2007, 2008 and 2009, covering periods before and after the opening of line 5, line 8 and line 10, as shown in figure 1. Line 5, opened in October 2007, goes north and south. It runs for $28 \mathrm{~km}$ and has 23 stations. Lines 8 and 10, opened in July 2008, go from west to east and then turn south. They run for $29 \mathrm{~km}$ and have 26 stations. There are two reasons why the three lines are of particular interest. One reason is that these three lines go in different directions and cover wide areas

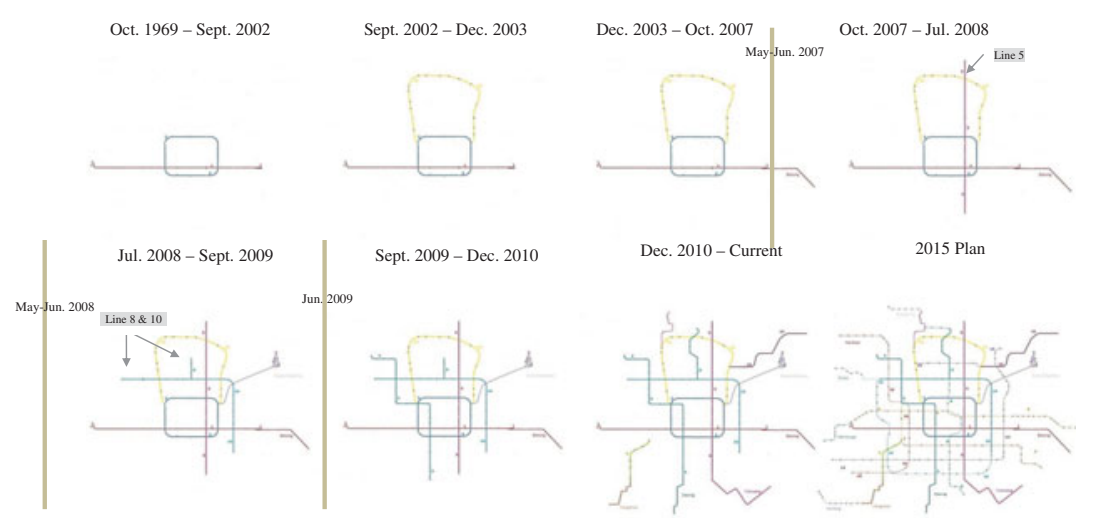

Figure 1. Beijing subway system expansion history and 2015 plan

Note: The vertical lines show survey dates relative to the subway expansion. Between the three rounds of surveys, line 5, line 8 and line 10 started operation. 
which are geographically representative. Beijing's development is based on the expansion of ring roads, all centered at Tiananmen Square. Residential areas within the inner rings tend to be wealthier. As shown in figure 2, lines 5, 8 and 10 cut vertically and horizontally across several rings. Therefore, the areas covered by these three lines are representative of different income levels. The other reason is that these three lines operate mainly within urban Beijing, an area that is highly populated and developed. Restricted by the land available for new housing projects, the migration rate in this area is relatively low. Renters can migrate without new housing projects, but this is limited by the supply in rental markets. Therefore, the self-selective bias is limited. This hypothesis is tested indirectly in a later section.

The travel diary data are from the Beijing Household Travel Survey (BHTS) done by the Beijing Transportation Center (BTC) every year since the 1980s. In each of the eight urban districts, households are randomly selected, stratified by traffic analysis zone (TAZ). TAZs are geocoded areas, divided by the BTC for the purpose of traffic analysis. Each administrative district has 16-238 TAZs, based on the size of the area and the population of a district. In each TAZ, about 25 households are randomly selected for interviews in person to collect data on trips taken during a designated 24-hour period. In this paper, the sample is restricted to the 71 TAZs that are surveyed in all three years, which is referred to as the TAZ panel. This restriction is to ensure the comparability of the commuters across years, because the data are repeatedly cross-sectional at the commuter level, although they are panel data at the TAZ level.

The survey gathers: (1) information about each segment of a trip taken during the household's travel day, including travel purpose (e.g., going to work, shopping, transferring ${ }^{3}$ ), travel mode (e.g., auto, bus, subway), travel distance, time when the travel began and ended and the TAZ code of the origin and the destination; (2) household information, including the TAZ code of the residence, vehicle ownership and monthly household income (levels 1-8); and (3) household member information, including gender, age, occupation, possession of a driver's license, and the TAZ code of the school (if a student) or the place of work (if an employee). Fourteen modes in the surveys are aggregated into four broader categories: (1) subway; (2) bus (including regular bus, minibus and shuttle); (3) auto (including driving/riding in a private/company auto, and taxi); and (4) walking and bicycling.

To measure the improvement in rail transit accessibility, each TAZ's proximity to rail transit is calculated in 2007, 2008 and 2009, using the digital map of TAZs from the BTC and the map of subway stations from the OpenStreetMap database. The proximity is measured as the distance between a TAZ's centroid and its nearest rail station. All households from

3 Transferring means switching modes. It can be the purpose of a trip segment, but cannot be the purpose of a trip. In this paper, a trip is defined as traveling between two places with a specific purpose, excluding going to subway/bus stations, taking a taxi, transferring and parking. Only one mode is involved in one segment of a trip, although a trip can have more than one mode. 

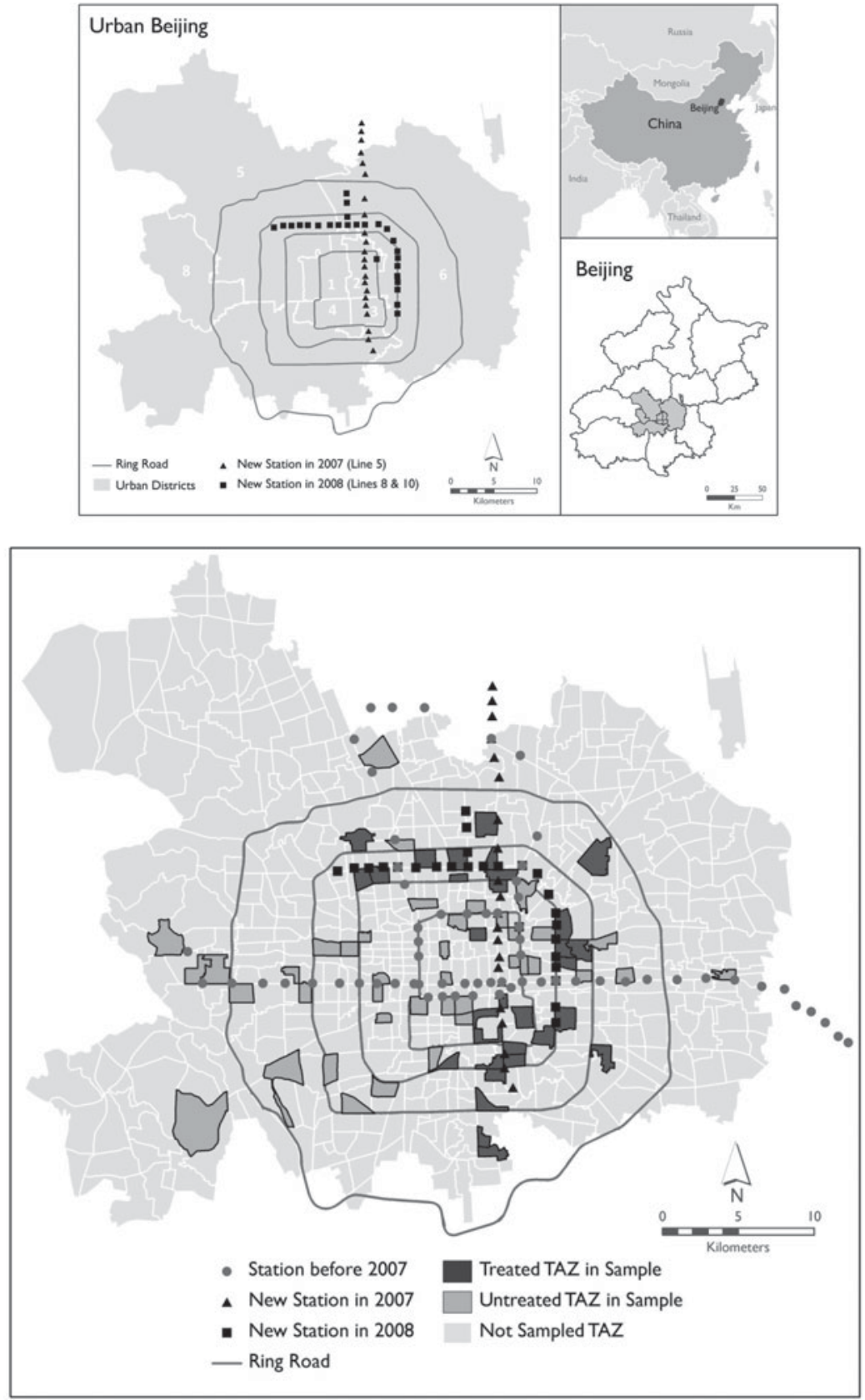

Figure 2. Map of Beijing and subway lines 5, 8, and 10 Note: The area studied in this paper is urban Beijing, including the eight administrative districts at the center of Beijing. Line 5, line 8 and line 10 cut the ring roads vertically and horizontally. 71 TAZs are surveyed in all three years from 2007 to 2009. A TAZ is defined as treated if its distance to the nearest subway station decreased in 2008 or 2009. In the sample, $31 \mathrm{TAZs}$ are treated and $40 \mathrm{TAZs}$ are not treated. 
the same TAZ are treated as residing at the same point. ${ }^{4}$ This approximation is acceptable, because TAZs in urban Beijing are small. The average area of a TAZ is less than $1.5 \mathrm{~km}^{2}$.

A TAZ is defined as 'treated' if its distance to the nearest subway station decreased in 2008 (after the opening of line 5) or 2009 (after the opening of lines 8 and 10). All treated TAZs are referred to as the treatment group, and all untreated TAZs as the control group. There are 31 and 40 TAZs in the two groups, respectively. In the treatment group, 19 TAZs are treated after the first round of surveys, while the other 12 TAZs are not treated until after the first two rounds of surveys. They are referred to as the early treatment group and the late treatment group, respectively.

Focus is placed on work trips, defined to include going to work and going to school, for two reasons. First, most road congestion happens during rush hours. Secondly, decisions about the destination and the travel mode are usually made jointly, especially for trips for which the destinations are easy to change, such as shopping trips. It takes much longer to change the place of work or school. Therefore, the mode choice is isolated from the destination choice by restricting the sample to work trips.

The mode usage of a trip is measured as the percentage distance traveled using that mode. ${ }^{5}$ Therefore, the mode usage of a trip is characterized by four continuous variables (percentage distance by subway, auto, bus, and walking and bicycling). As shown in table 1, the average percentage distance in work trips traveled by auto is around 30 per cent, which is the second largest share, next to the distance by walking and bicycling. Although subway usage is a small share of work trips, the share increased from year to year in the treatment group.

In addition to the mode usage of a work trip, the number of work trips and the trip distance are also of interest. One way to measure trip distance is to add up the reported distances of the trip segments. The reported distance is affected by the choices of routes and travel modes and might be subject to reporting bias. To avoid these confounding factors, the point-topoint distance between the centroids of the origin and destination TAZs is also measured. For all trips traveling within a TAZ, the measured trip distance is zero.

A TAZ which is not treated directly may also be affected by the subway expansion through congestion alleviation. The intensity of the spillover from TAZ $i$ to TAZ $j$ is measured by the number of trips from TAZ $i$ to

4 This is the only way to locate a household in the survey. Due to the confidentiality requirements for human subjects, all information that can identify a household or a person, such as names and home addresses, is removed from the data set.

5 The travel distances by each mode are reported values from the surveyed individuals, and they might be subject to reporting bias. For example, individuals may misreport the distances traveled in a new mode chosen or a mode with which they are not satisfied. To limit the effect of reporting bias, I experiment, in section 3.1, with defining mode usage as a dummy variable indicating whether the mode under discussion is the main mode of a trip. The regression results are robust to the alternative definition of the dependent variable. 
Table 1. Summary statistics

\begin{tabular}{|c|c|c|c|c|c|c|c|}
\hline \multirow[b]{3}{*}{ Group } & \multirow[b]{3}{*}{ Variable } & \multicolumn{6}{|c|}{$\begin{array}{l}31 \text { TAZs in the treatment group per year } \\
40 \mathrm{TAZs} \text { in the control group per year }\end{array}$} \\
\hline & & \multicolumn{2}{|c|}{2007} & \multicolumn{2}{|c|}{2008} & \multicolumn{2}{|c|}{2009} \\
\hline & & Mean & S.D. & Mean & S.D. & Mean & S.D. \\
\hline \multirow[t]{17}{*}{ Treatment } & Subway usage (0-1) & 0.0254 & 0.1353 & 0.0298 & 0.1557 & 0.0451 & 0.1858 \\
\hline & Auto usage (0-1) & 0.3031 & 0.4522 & 0.2991 & 0.4450 & 0.2829 & 0.4395 \\
\hline & Bus usage $(0-1)$ & 0.2622 & 0.4020 & 0.2063 & 0.3747 & 0.2316 & 0.3768 \\
\hline & Walking and bicycling $(0-1)$ & 0.4093 & 0.4516 & 0.4649 & 0.4639 & 0.4403 & 0.4469 \\
\hline & Reported trip distance $(\mathrm{km})$ & 7.9260 & 9.0572 & 8.4156 & 11.0727 & 6.8325 & 8.7739 \\
\hline & Measured trip distance $(\mathrm{km})$ & 6.0555 & 5.8674 & 5.4826 & 6.2933 & 5.4519 & 6.1698 \\
\hline & Number of trips per day & 1.0699 & 0.2781 & 1.0430 & 0.2134 & 1.0631 & 0.2432 \\
\hline & Number of trips into a TAZ & 1.0858 & 0.9244 & 1.9470 & 1.5596 & 2.0959 & 2.3348 \\
\hline & Number of trips into a TAZ from the treated & 0.0000 & 0.0000 & 1.0991 & 1.4106 & 1.7023 & 2.0465 \\
\hline & $\begin{array}{l}\text { Distance between residence and the nearest } \\
\text { subway station }(\mathrm{km})\end{array}$ & 2.8215 & 1.9030 & 1.9638 & 1.2359 & 1.3823 & 1.1936 \\
\hline & Road coverage in a TAZ $(\mathrm{km})$ & 14.6292 & 8.007 & 14.6292 & 8.007 & 14.6292 & 8.007 \\
\hline & Number of bus stops in a TAZ & 13.3226 & 5.049 & 13.3226 & 5.049 & 13.3226 & 5.049 \\
\hline & Auto ownership $(1=$ with, $0=$ without $)$ & 0.5044 & 0.5003 & 0.5172 & 0.4999 & 0.5718 & 0.4950 \\
\hline & Driver's license $(1=$ with, $0=$ without $)$ & 0.4945 & 0.5002 & 0.4044 & 0.4910 & 0.4310 & 0.4954 \\
\hline & Income (level 1-8) & 3.6921 & 1.1980 & 4.0237 & 1.1425 & 4.2746 & 0.9234 \\
\hline & Gender $(1=$ male, $0=$ female $)$ & 0.5382 & 0.4988 & 0.5752 & 0.4945 & 0.5551 & 0.4972 \\
\hline & Age & 35.1921 & 14.4804 & 35.3448 & 14.3515 & 35.8378 & 13.6872 \\
\hline
\end{tabular}




\begin{tabular}{|c|c|c|c|c|c|c|c|}
\hline \multirow[t]{17}{*}{ Control } & Subway usage $(0-1)$ & 0.0474 & 0.1888 & 0.0450 & 0.1917 & 0.0465 & 0.1897 \\
\hline & Auto usage $(0-1)$ & 0.2663 & 0.4350 & 0.3088 & 0.4452 & 0.3140 & 0.4487 \\
\hline & Bus usage $(0-1)$ & 0.2258 & 0.3801 & 0.2057 & 0.3721 & 0.2422 & 0.3884 \\
\hline & Walking and bicycling (0-1) & 0.4605 & 0.4600 & 0.4405 & 0.4556 & 0.3974 & 0.4377 \\
\hline & Reported trip distance $(\mathrm{km})$ & 7.6615 & 9.8145 & 9.3814 & 12.0682 & 7.6423 & 8.8726 \\
\hline & Measured trip distance $(\mathrm{km})$ & 5.9000 & 6.7522 & 5.9230 & 6.7945 & 6.3420 & 6.8895 \\
\hline & Number of trips & 1.0567 & 0.2444 & 1.0362 & 0.1869 & 1.0664 & 0.2799 \\
\hline & Number of trips into a TAZ & 1.4855 & 1.7907 & 2.1849 & 4.0547 & 1.9977 & 2.8700 \\
\hline & Number of trips from the treated & 0.0000 & 0.0000 & 0.1087 & 0.1320 & 0.2593 & 0.3604 \\
\hline & $\begin{array}{l}\text { Distance between residence and the nearest } \\
\text { subway station }(\mathrm{km})\end{array}$ & 1.6420 & 1.7323 & 1.6914 & 1.8709 & 1.8576 & 1.9750 \\
\hline & Road coverage in a TAZ & 14.3628 & 9.7058 & 14.3628 & 9.7058 & 14.3628 & 9.7058 \\
\hline & Number of bus stops in a TAZ & 12.7000 & 8.5070 & 12.7000 & 8.5070 & 12.7000 & 8.5070 \\
\hline & Auto ownership $(1=$ with, $0=$ without $)$ & 0.4644 & 0.4989 & 0.5264 & 0.4995 & 0.5580 & 0.4968 \\
\hline & Driver's license $(1=$ with, $0=$ without $)$ & 0.4063 & 0.4913 & 0.4374 & 0.4962 & 0.4504 & 0.4977 \\
\hline & Income (level 1-8) & 3.6209 & 1.1746 & 4.2543 & 1.0461 & 4.3817 & 0.9174 \\
\hline & Gender $(1=$ male, $0=$ female $)$ & 0.5151 & 0.5000 & 0.5544 & 0.4972 & 0.5705 & 0.4952 \\
\hline & Age & 36.0118 & 15.0115 & 34.9828 & 14.1462 & 35.9651 & 13.4792 \\
\hline
\end{tabular}

Notes: The summary statistics of the work trips from the balanced sample of TAZs (71 TAZs that are surveyed in all three years) are reported. Mode usage variables are calculated by dividing the reported distances of a mode by the total trip distance, which is the summation of reported distances of all trip segments (variable: reported trip distance). The reported distances could be subject to reporting bias. Therefore, the point-to-point distance between the centroids of the origin and destination TAZs (variable: measured trip distance) is also measured. We see that the two trip distance variables evolve differently. Therefore, to limit the effect of reporting bias on the results, I experiment with an alternative definition of mode usage (the main mode of a trip) in section 3.1. The results remain stable to this alternative definition. 
TAZ $j .{ }^{6}$ Therefore, the complete indirect effect on TAZ $j$ is measured as the summation of the number of trips from all TAZs, and the indirect effect on TAZ $j$ from the treatment is measured as the summation of the number of trips from treated TAZs.

In addition to accessibility of rail transit, mode usage is also influenced by traffic infrastructure characteristics, such as road coverage and number of bus stops. The spatial distribution of roads and bus stops in Beijing is taken from the OpenStreetMap database. Using this information, together with the digital map of TAZs, the road coverage and the number of bus stops for each TAZ are calculated.

Table 1 provides summary statistics of dependent variables (i.e., mode usage for work trips, number of trips and trip distance), variables to measure indirect effects, variables characterizing traffic infrastructure conditions, and demographic variables by group in 2007, 2008 and 2009.

\section{Estimation strategies and results}

In this section, the effect of the subway expansion on percentage distance traveled by various modes is estimated. The plausibility of some key assumptions is then tested.

\subsection{Estimation of the subway expansion effect}

Interest is centered primarily on estimating the sample average treatment effect on the treated (SATT) for each mode $m$, using the DID estimator:

$$
\alpha_{T T}^{m}=\left(\bar{Y}_{11}^{m}-\bar{Y}_{10}^{m}\right)-\left(\bar{Y}_{01}^{m}-\bar{Y}_{00}^{m}\right)
$$

where $\bar{Y}_{s t}^{m}=\frac{1}{\mathrm{~N}_{\mathrm{st}}} \sum_{i} Y_{i s t}^{m} ; s$ equals 1 for the treatment group, and 0 for the control group; $t$ equals 0 when the observation is before the treatment, and 1 after the treatment. $Y_{i s t}^{m}$ is the percentage distance traveled in mode $m$ by commuter $i$ in group $s$ at time $t$.

In order to reduce the bias potentially introduced by observable differences between residents in the treatment and control groups, a regressionbased conditioning strategy is employed. With multiple time periods (three years, including 30 survey dates) and multiple groups (71 TAZs), a natural extension of the two-group-two-time-period model (Imbens and Wooldridge, 2009) is used.

This regression-based DID estimator will be biased if travel behaviors of the control group are affected by the subway expansion. One potential

${ }^{6}$ This measurement ignores the spillover effect of cross-zone traffic, because a trip that crosses TAZ $j$ and ends at TAZ $k$ contributes to the congestion at TAZ $j$, but will not be counted by our measurement. Given that information on travel routes is lacking, an alternative way to control for the spillover effect of cross-zone traffic is to control for the road net characteristics of TAZs, because TAZs with ring roads or primary roads are more likely to be trespassed, compared to TAZs without such large capacity roads. Because road net characteristics are time invariant and therefore are captured in TAZ dummies, the spillover effect of cross-zone traffic is accounted for in all the regressions which have TAZ dummies. 
channel through which an indirect effect could work is traffic congestion alleviation. This could occur if subway expansion diverts autos from the treated area. If so, congestion would be alleviated not only in the treated area, but also in the control area; commuters in the control area would then respond to the improved traffic conditions by driving more. Such cross-area externality is addressed by taking advantage of variation in the intensity of the spillover from the treated areas. The spillover intensity from treated area $i$ to area $j$ is measured, ex ante, as the number of trips from area $i$ to area $j$.

The average treatment effects of subway expansion on the treated, as well as cross-area treatment externality, is estimated as:

$$
\begin{aligned}
Y_{i z d t}^{m}= & \alpha+\boldsymbol{\beta}^{\prime} \boldsymbol{X}_{i t}+\tau D_{z t}+\gamma\left(\sum_{j} \text { trips }_{j z}\right)+\theta\left(\sum_{j \in T} \text { trips }_{j z}\right) \\
& +C_{z}+\eta_{t}+\varphi_{d t}+v_{i z d t}
\end{aligned}
$$

where $Y_{i z d t}^{m}$ is the percentage distance traveled in mode $m$ by commuter $i$ residing in TAZ $z$ at district $d$ and observed at time $t ; X_{i t}$ is a vector of observable covariates for commuter $i$ observed at time $t ; D_{z t}$ is the treatment indicator, which equals 1 if $\operatorname{TAZ} z$ is treated at time $t, 0$ otherwise; $\sum_{j}$ trips $_{j z}$ is the total number of trips, scaled by the length of roads in TAZ $z$, from all TAZs to TAZ $z$, and $\sum_{j \in T}$ trips $_{j z}$ is the number of trips from all treated TAZs to TAZ $z ; c_{z}$ are TAZ dummies; $\eta_{t}$ are time dummies; $\varphi_{d t}$ are district-by-year dummies; and $v_{i z d t}$ is the residual.

Given the total number of trips from all TAZs to TAZ $z$, the number of trips from the treated TAZs to TAZ $z$ is exogenous, since the treatment is exogenous to the characteristics of TAZ $z \cdot{ }^{7}$ The parameter $\tau$ captures the average effect of the subway expansion on changes in individuallevel travel mode usage over time, conditional on variables in $X$. The parameter $\theta$ captures the cross-area treatment externality on the untreated TAZs.

Results are reported in table 2 . In column (1), the basic specification, the mode usage is regressed on the treatment indicator, the group indicator and year dummies. The group indicator equals 1 if the commuter is residing in a treated TAZ, 0 otherwise. In column (2), TAZ dummies and survey date dummies are used, which are finer dummies than the group indicator and the year dummies. In the following columns, demographic variables are added in, which are related to mode usage. Extra caution is exercised when including auto ownership in $X$, because it is influenced by the treatment. When subway accessibility is improved, auto ownership

7 According to the Beijing Transportation Commission and the civil planning department, the rollout of the new subway lines mainly depends on the underground geological framework, instead of the characteristics of an individual TAZ. Besides, according to the 2015 plan, the whole area will be covered by subway lines in only a few years. Getting a subway line several years earlier does not really make a difference to a TAZ. 
Table 2. Effect of subway expansion on mode usage

Dep. variable: percentage distance traveled by a mode (= distance by a mode/trip distance)

(1) (2) (3) (4) (5)

\section{Panel A. subway}

Treatment

$$
\begin{array}{lllll}
0.0241^{* * *} & 0.0176^{* *} & 0.0248^{* * *} & 0.0250^{* * *} & 0.0273^{* * *} \\
(0.0089) & (0.0083) & (0.009) & (0.009) & (0.0092)
\end{array}
$$

Number of trips from the treated

\section{Panel B. Auto}

Treatment

$$
\begin{array}{ccccc}
-0.0446^{* *} & -0.0504^{* *} & -0.0651^{* *} & -0.0601^{* * *} & -0.0489^{* *} \\
(0.0204) & (0.0234) & (0.0250) & (0.0221) & (0.0223) \\
& & & & -0.0086
\end{array}
$$

Number of trips from the treated

\section{Panel C. Bus}

Treatment

$$
\begin{array}{ccccc}
-0.0249 & -0.0201 & -0.0116 & -0.0132 & -0.0189 \\
(0.0230) & (0.0228) & (0.0244) & (0.0229) & (0.0261) \\
& & & & 0.0065 \\
& & & & (0.0077)
\end{array}
$$

Number of trips

from the treated

\section{Panel D. Walking and bicycling}

Treatment

$$
\begin{array}{ccccc}
0.0454 & 0.0528 & 0.0519^{* *} & 0.0483^{* *} & 0.0406^{*} \\
(0.0345) & (0.0339) & (0.0224) & (0.0224) & (0.0217) \\
& & & & 0.0031 \\
& & & & (0.0105)
\end{array}
$$

Number of trips from the treated

Group indicator

Year dummies

TAZ dummies

Survey date dummies

District by year dummies

Income, gender, age, occupation

Auto ownership, driver's license

$\mathrm{x}$

$\mathrm{x}$

$\mathrm{x}$

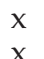

$x$

$\mathrm{x}$

$\mathrm{x}$

$\mathrm{x}$

$x$

$\mathrm{x}$

$\mathrm{x}$

$\mathrm{x}$

$x$

$\mathrm{x}$

x $\quad x$

Cross-area treatment externality

Number of observations

Notes: Observations are at individual trip level. Only work trips are studied in this paper. The specification in each column is indicated in the lower part of the table. The full results are available in appendix A. Standard errors are clustered at the TAZ level. ${ }^{*}, * *,{ }^{* * *}$ indicate $10 \%, 5 \%$ and $1 \%$ significance level, respectively. 
may become less attractive. Therefore, subway expansion affects the mode usage not only directly by diverting commuters, but also indirectly by decreasing the demand for auto ownership. The coefficient of the treatment indicator catches both of the effects when not controlling for auto ownership, while it catches only the direct effect if controlling for auto ownership. In columns (3) and (4), the regression is run without and with auto ownership, respectively. In column (5), the measure of spillover intensities is added in.

Table 2 shows evidence of a positive and statistically significant effect of the subway expansion on subway usage and a negative and statistically significant effect on auto usage in all five specifications. The effect on bus usage is not statistically significant. The effect on walking and bicycling is statistically significant when controlling for demographic variables. A comparison of columns (3) and (4) shows that the effects remain stable to the control for auto ownership. This indicates that the indirect effect of the subway expansion on mode usage through changing the demand for auto ownership is small. This finding is confirmed by comparing the auto ownership trajectories between the treatment group and the control group. The graphic analysis and the regression results on auto ownership are available upon request.

Column (5) is the full specification and shows the main result. Panel A indicates that a decrease in the distance to the station increased the percentage distance traveled by subway by 0.0273 (from 0.0254 to 0.0527 ), which is a 107 per cent change. Panel B shows that the percentage distance traveled by auto decreased by 0.0489 (from 0.3031 to 0.2542 ), which is a 16 per cent change. Panel $\mathrm{C}$ shows that the effect on the percentage distance traveled by bus is 0.0189 (from 0.2622 to 0.2433 ), which is a 7 per cent decrease and not statistically significant. Panel D shows that the percentage distance traveled by walking and bicycling increased by 0.0406 (from 0.409 to 0.4496 ), which is a 10 per cent increase. These results indicate that the subway expansion diverted commuters from auto towards subway, while having no significant effect on bus passengers. The increase in the walking and bicycling distance indicates that walking and bicycling are complements to subway travel, rather than substitutes. The estimated coefficients of number of trips from the treated are small and not statistically significant. This suggests that the cross-area externality is not large enough within the studied areas and the time span studied to affect the travel behaviors of commuters in the control areas. This finding is consistent with Yang et al. (2015). They investigated the impact of subway expansion in Beijing from 2009 to 2013 on traffic congestion and found that congestion was not significantly alleviated. The full results of the main regression are available in appendix A.

I also experiment with the definition of mode usage. Now, mode usage is defined as a binary variable which equals 1 if subway, bus, auto, or walking and bicycling is the main mode of the trip, and equals 0 otherwise. The main mode is defined as the mode covering the greatest distance of a trip. The regression results, which are available upon request, show that the estimates remain stable to the alternative definition of mode usage. 


\subsection{Evaluating the underlying assumptions}

In order to interpret these estimates as an unbiased measure of the subway expansion impacts, some important assumptions must hold - in particular, conditional unconfoundedness and stable unit treatment values.

\subsubsection{Assessing unconfoundedness}

The above analysis assumes that the mode usage has similar trajectories for the two groups over time, absent any treatment effect, conditional on observable individual characteristics. This assumption is not observable and therefore not testable in principle. One possible way to assess the plausibility of this assumption is to test whether the two groups had similar usage trajectories before the treatment. Due to data availability, the full sample is observed only once before the treatments. Therefore, the pre-treatment trajectories of the late treatment group, instead of the full treatment group, are compared to those of the control group. If the pre-treatment usage trajectories indeed are similar, the double difference $\left(\bar{Y}_{g_{2,2008}}^{m}-\bar{Y}_{g_{2,2007}}^{m}\right)-\left(\bar{Y}_{g_{1,2008}}^{m}-\bar{Y}_{g_{1,2007}}^{m}\right)$ should be 0 , where $g_{1}$ is the control group, and $g_{2}$ is the late treatment group. A fake treatment indicator is defined, which equals 1 for the late treatment group in 2008, 0 otherwise. The sample is restricted to the two groups in 2007 and 2008, and the mode usage is regressed on the fake treatment indicator, year dummies, TAZ dummies, district by year dummies and demographic variables. The coefficient of the fake treatment indicator is expected to be 0 . As shown in panel A of table 3, the estimates for all four modes are indeed small and not statistically significant.

\subsubsection{Assessing the stability of unit treatment values}

The estimation strategy also requires that the potential mode usage of one individual is independent of the treatment status of other individuals. There are two potential ways in which this assumption might be violated. One way is through traffic congestion alleviation, which we have addressed by including the cross-area externality in the regressions. The second potential violation of the assumption is through self-selective migration. If untreated commuters who prefer the subway are attracted to the treated TAZs, this would decrease the average subway usage of the control group, and exaggerate the estimates of the subway expansion impacts. Lacking migration data or panel data at the household level, the violation of the assumption is not empirically tractable, unless we generate a specific hypothesis regarding how the violation would manifest itself. The hypothesis is as follows: some commuters prefer the subway, but live farther away for reasons such as the high housing prices and limited housing supply in the nearby areas. The new lines put more areas within walking distance, and therefore may induce the migration of these commuters. If this kind of migration exists, we would expect to find smaller treatment effects when the control group is restricted to nearby TAZs. Panel B of table 3 reports SATT estimates obtained using only data from TAZs within a $2-\mathrm{km}$ distance of a subway station as controls. They are similar to the results from the main regressions. This suggests that self-selective migration, if any, 
Table 3. Indirect test of unconfoundedness

\begin{tabular}{|c|c|c|c|c|}
\hline & \multicolumn{4}{|c|}{$\begin{array}{l}\text { Dep. variable: percentage distance traveled by a mode } \\
(=\text { distance by a mode/trip distance })\end{array}$} \\
\hline & (1) & (2) & (3) & (4) \\
\hline & Subway & Auto & Bus & $\begin{array}{l}\text { Walking and } \\
\text { bicycling }\end{array}$ \\
\hline \multicolumn{5}{|l|}{ Panel A. Fake treatment } \\
\hline & $\begin{array}{c}-0.0039 \\
(0.0152)\end{array}$ & $\begin{array}{c}0.0244 \\
(0.0250)\end{array}$ & $\begin{array}{c}-0.0243 \\
(0.0293)\end{array}$ & $\begin{array}{c}0.0038 \\
(0.0299)\end{array}$ \\
\hline Number of observations & 3,715 & 3,715 & 3,715 & 3,715 \\
\hline \multicolumn{5}{|l|}{ Panel B. Migration } \\
\hline & $\begin{array}{c}0.0204^{*} \\
(0.0119)\end{array}$ & $\begin{array}{c}-0.0468^{* *} \\
(0.0229)\end{array}$ & $\begin{array}{c}-0.0230 \\
(0.0292)\end{array}$ & $\begin{array}{c}0.0494^{*} \\
(0.0250)\end{array}$ \\
\hline Number of observations & 6,404 & 6,404 & 6,404 & 6,404 \\
\hline
\end{tabular}

Notes: Panel A tests whether the pre-treatment mode usage trajectories are similar between the late treatment group and the control group. The sample is restricted to those in the control group and the late treatment group in 2007 and 2008. Panel B tests the plausibility of the SUTVA assumption. The control group is restricted to the TAZs that are within a $2-\mathrm{km}$ radius circle of a subway station. The specifications in both panels are the same as the main regression. Standard errors are clustered at the TAZ level. ${ }^{*}, * *, * * *$ indicate $10 \%, 5 \%$ and $1 \%$ significance level, respectively.

is not large enough to bias the estimated expansion effects significantly. This is as expected, as mentioned in the data section. In highly populated urban Beijing, without excess housing supply, large migration is not likely to happen within a one-year time span.

\subsection{Treatment effect heterogeneity}

In this subsection, four types of treatment effect heterogeneity are investigated. First, continuous treatment is considered. Next, variation of the effects across areas with different traffic infrastructure conditions is investigated. Then, the question of whether the effects are correlated with demographics is explored. Finally, the effects of the rail accessibility improvement at the destination are studied.

\subsubsection{Continuous treatment}

Both the distance reduction and the resultant distance to the nearest subway station are continuous. We expect to see different mode usage changes across the groups that experienced different reductions in distance and different distances as a result. To allow for such differences, $\varphi D_{z t} * d i s t_{z t}+$ $\mu$ dist $_{z t}$ is added in equation (2), where dist ist $_{\text {in }}$ is the distance between TAZ $z$ and its nearest subway station at time $t$. Denoting the distance before and after the subway expansion as $d_{0}$ and $d_{1}$, respectively, the effect of subway expansion can then be expressed as $\tau+\varphi d_{1}+\mu\left(d_{1}+d_{0}\right)$, where $d_{1}+d_{0}$ 
measures distance reduction. As shown in table 4, panel A, $\varphi$ is estimated as negative in the subway regression, and positive in the auto regression; $\mu$ is estimated as small and not statistically significant in all regressions. This suggests that the diversion effect of subway expansion depends on whether the expansion brings a subway station to commuters' residential places, rather than how large the distance reduction was; that is, the resultant distance matters, while the magnitude of improvement does not.

\subsubsection{Heterogeneous treatment effects across traffic infrastructure conditions}

To investigate the heterogeneous treatment effects across TAZs with different traffic infrastructure conditions, $\boldsymbol{\delta}^{\prime} \boldsymbol{Z}_{z t} D_{z t}$ is added in equation (2), where $Z_{z t}$ is a vector, including road coverage and the number of bus stops in TAZ $z$ at time $t$. As shown in table 4, panel B, the estimated coefficient of treatment $\times$ road coverage is negative for subway, positive for auto and negative for bus. It suggests that, in the areas with an extensive road system, a new subway line is less attractive, compared to areas with less road coverage. In an area with more road coverage, the additional subway passengers are less likely to be commuters who previously drove to work and more likely to be previous bus passengers. This is expected, because commuters in areas with more road coverage are likely to have had good experiences when driving, so they will not bother to switch from driving to subway when there is a new subway line. The coefficient of treatment $\times$ number of bus stops is positive for subway and auto, while it is negative for bus. This suggests that a new line in areas with a large public transit system is more attractive, compared to an isolated line. Its passengers are more likely to be previous bus passengers, while they are less likely to be auto drivers. To summarize, a new subway line in an area with a smaller road system but a larger public transit system will have better ridership; however, if the goal of this new line is to attract as many auto drivers as possible, it is better to place the new line in areas with less road coverage and fewer bus stops.

\subsubsection{Heterogeneous treatment effects across demographics}

To investigate the effect of heterogeneity across auto ownership, $\boldsymbol{\delta}^{\prime} \boldsymbol{X}_{i t} D_{z t}$ is added in equation (2), where auto ownership, driver's license, interaction of auto ownership and driver's license, and income are included in $\boldsymbol{X}$. An auto owner is defined as an individual who has a driver's license and is a member of a household that has one or more autos. As shown in table 4, panel $C$, the estimated coefficient of treatment $\times$ auto ownership $\times$ driver's license and that of treatment $\times$ income are negative in the auto regression, indicating that auto usage by auto owners and commuters with higher income decreased more, compared to commuters without an auto or a driver's license and those with lower income. This is straightforward because auto owners and commuters with higher income have much greater auto usage to begin with. This finding is consistent with the finding of Yang et al. (2015) that new subway lines in outer Beijing, where the residents have a lower income than those of urban Beijing, have little effect on traffic congestion. Therefore, the impacts are also measured as percentage 
Table 4. Heterogeneity in treatment and treatment effect

\begin{tabular}{|c|c|c|c|c|}
\hline & \multicolumn{4}{|c|}{$\begin{array}{c}\text { Dep. variable: percentage distance traveled } \\
\text { by a mode (= distance by a mode/trip distance) }\end{array}$} \\
\hline & Subway & Auto & Bus & $\begin{array}{l}\text { Walking and } \\
\text { bicycling }\end{array}$ \\
\hline \multicolumn{5}{|c|}{ Panel A. Continuous treatment } \\
\hline Treatment & $\begin{array}{l}0.0401^{* *} \\
(0.0156)\end{array}$ & $\begin{array}{l}-0.0874^{* * *} \\
(0.0327)\end{array}$ & $\begin{array}{c}-0.00098 \\
(0.0430)\end{array}$ & $\begin{array}{c}0.0483 \\
(0.0328)\end{array}$ \\
\hline $\begin{array}{l}\text { Treatment } \times \text { distance } \\
\text { of residence place to } \\
\text { subway }\end{array}$ & $\begin{array}{r}-0.0092^{*} \\
(0.0049)\end{array}$ & $\begin{array}{l}0.0255^{* *} \\
(0.0101)\end{array}$ & $\begin{array}{r}-0.0110 \\
(0.0110)\end{array}$ & $\begin{array}{r}-0.0053 \\
(0.0106)\end{array}$ \\
\hline $\begin{array}{l}\text { Distance between res- } \\
\text { idence place and } \\
\text { subway }\end{array}$ & $\begin{array}{l}-0.0014 \\
(0.00401)\end{array}$ & $\begin{array}{c}0.0016 \\
(0.0116)\end{array}$ & $\begin{array}{c}0.0003 \\
(0.0115)\end{array}$ & $\begin{array}{r}-0.0005 \\
(0.0123)\end{array}$ \\
\hline \multicolumn{5}{|c|}{$\begin{array}{l}\text { Panel B. Treatment effect heterogeneity across TAZ traffic infrastructure } \\
\text { characteristics }\end{array}$} \\
\hline Treatment & $\begin{array}{l}0.0618^{* *} \\
(0.0259)\end{array}$ & $\begin{array}{l}-0.113^{*} \\
(0.0576)\end{array}$ & $\begin{array}{c}0.0395 \\
(0.0563)\end{array}$ & $\begin{array}{c}0.0113 \\
(0.0506)\end{array}$ \\
\hline Treatment $\times$ road length & $\begin{array}{c}-0.00284^{* *} \\
(0.00127)\end{array}$ & $\begin{array}{c}0.00303 \\
(0.00246)\end{array}$ & $\begin{array}{c}-0.000299 \\
(0.00236)\end{array}$ & $\begin{array}{c}0.000113 \\
(0.00191)\end{array}$ \\
\hline $\begin{array}{l}\text { Treatment } \times \text { number of } \\
\text { bus stops }\end{array}$ & $\begin{array}{c}0.00111 \\
(0.00131)\end{array}$ & $\begin{array}{r}0.000822 \\
(0.00383)\end{array}$ & $\begin{array}{c}-0.00397 \\
(0.00328)\end{array}$ & $\begin{array}{l}0.00204 \\
(0.00363)\end{array}$ \\
\hline \multicolumn{5}{|c|}{ Panel C. Treatment effect heterogeneity across socio-economic characteristics } \\
\hline Treatment & $\begin{array}{c}0.0186 \\
(0.0213)\end{array}$ & $\begin{array}{r}-0.0338 \\
(0.0461)\end{array}$ & $\begin{array}{r}-0.0195 \\
(0.0478)\end{array}$ & $\begin{array}{c}0.0347 \\
(0.0529)\end{array}$ \\
\hline $\begin{array}{l}\text { Treatment } \times \text { auto } \\
\text { ownership } \times \text { driver's } \\
\text { license }\end{array}$ & $\begin{array}{c}0.0358 \\
(0.0253)\end{array}$ & $\begin{array}{r}-0.119^{* *} \\
(0.0483)\end{array}$ & $\begin{array}{c}0.0190 \\
(0.0458)\end{array}$ & $\begin{array}{c}0.0642 \\
(0.0494)\end{array}$ \\
\hline $\begin{array}{l}\text { Treatment } \times \text { auto } \\
\text { ownership }\end{array}$ & $\begin{array}{c}0.0118 \\
(0.0152)\end{array}$ & $\begin{array}{l}0.0604^{* *} \\
(0.0262)\end{array}$ & $\begin{array}{r}-0.0177 \\
(0.0322)\end{array}$ & $\begin{array}{r}-0.0544 \\
(0.0330)\end{array}$ \\
\hline $\begin{array}{l}\text { Treatment } \times \text { driver's } \\
\text { license }\end{array}$ & $\begin{array}{r}-0.0384^{*} \\
(0.0198)\end{array}$ & $\begin{array}{c}0.0330 \\
(0.0304)\end{array}$ & $\begin{array}{c}-0.0037 \\
(0.0409)\end{array}$ & $\begin{array}{c}0.0092 \\
(0.0344)\end{array}$ \\
\hline Treatment $\times$ income & $\begin{array}{c}0.0015 \\
(0.0059)\end{array}$ & $\begin{array}{r}-0.0056 \\
(0.0101)\end{array}$ & $\begin{array}{c}0.0014 \\
(0.0096)\end{array}$ & $\begin{array}{c}0.0027 \\
(0.0117)\end{array}$ \\
\hline \multicolumn{5}{|c|}{ Panel D. Effects of the treatment at destination } \\
\hline Treatment & $\begin{array}{l}0.0286^{* * *} \\
(0.0101)\end{array}$ & $\begin{array}{r}-0.0459^{*} \\
(0.0245)\end{array}$ & $\begin{array}{r}-0.0176 \\
(0.0271)\end{array}$ & $\begin{array}{l}0.0348^{*} \\
(0.0209)\end{array}$ \\
\hline Treatment at destination & $\begin{array}{c}-0.00439 \\
(0.00870)\end{array}$ & $\begin{array}{c}-0.00953 \\
(0.0198)\end{array}$ & $\begin{array}{c}-0.00417 \\
(0.0203)\end{array}$ & $\begin{array}{c}0.0181 \\
(0.0218)\end{array}$ \\
\hline Number of observations & 7,547 & 7,547 & 7,547 & 7,547 \\
\hline
\end{tabular}

Notes: Each panel has the same specification as the main regression, except for additional interaction terms for panels $A$ through $C$ and the additional treatment indicator (treatment at destination) for panel D. Standard errors are clustered at the TAZ level. ${ }^{*},{ }^{* *},{ }^{* * *}$ indicate $10 \%, 5 \%$ and $1 \%$ significance level, respectively. 
changes, and it is found that auto owners and commuters with a higher income are less likely to be diverted from autos towards the subway. The calculation and comparison are available in appendix B.

\subsubsection{Treatment at destination}

Rail accessibility is also improved when the distance between the place of work and a subway station is decreased. The effect of the treatment at destination is estimated by adding $\tau^{d} D_{z t}^{d}$ in equation (2). $D_{z t}^{d}$ is the indicator of treatment at destination, which equals 1 if the distance between the work TAZ and the nearest subway station is decreased at time $t, 0$ otherwise. As shown in table 4, panel D, the estimated coefficient of treatment at destination is small and not statistically significant in all regressions, and the estimated impacts of the treatment at origin are not changed significantly by the additional treatment indicator. This indicates that, conditional on the treatment at the origin, treatment at the destination has a minor impact on mode usage. A possible reason is that the main business areas are covered by the old subway lines. The main function of the new lines (lines 5, 8, and 10 ) is to collect and bring commuters to those major destinations. Therefore, the effect of treatment at origin is large, while the effect of treatment at destination is small. When all of urban Beijing is covered by subway lines, as in the 2015 Plan, we expect to see the effect of treatment at the destination for the additional lines.

\section{Effect on trip quantity}

As the expansion makes commuting faster and more convenient, commuters in the treatment group may respond to the convenience by making more or longer trips. ${ }^{8}$ In this section, the question is asked as to whether the subway expansion increased the number of trips and the trip length. Table 5 summarizes the results of estimating equation (2) with different dependent variables. In column (1), the dependent variable is the number of work trips taken by a commuter on a weekday. The estimate is small and not statistically significant. This indicates that commuters did not increase the frequency of work trips in response to the accessibility improvement. Columns (2) through (5) measure the effect of the expansion on trip distances. In columns (2) and (4), the trip distance is measured as the sum of reported distances of trip segments and the point-to-point distance measured on digital maps, respectively. Columns (3) and (5) take the natural logarithm of the reported distances and the measured distances, respectively. The estimates are small and not statistically significant in columns

${ }^{8}$ Besides inducing more or longer trips by commuters, subway expansion may also generate new trips from previous non-commuters through improving labor market access. This job trip generation effect could be an important source of trip generation of subway expansion. However, given that the new subway lines studied in this paper are all in urban Beijing, where the labor market was already fairly accessible by bus, the new job trip generation effect is left for future research which will study the more recent subway openings in outer Beijing. 
Table 5. Effects of subway expansion on number of trips and trip distance

\begin{tabular}{lccccc}
\hline & $(1)$ & $(2)$ & $(3)$ & $(4)$ & $(5)$ \\
\cline { 2 - 6 } Dep. variable & $\begin{array}{c}\text { Number of } \\
\text { trips }\end{array}$ & $\begin{array}{c}\text { Trip } \\
\text { distance }\end{array}$ & $\begin{array}{c}\text { Log } \\
\text { (trip distance) }\end{array}$ & $\begin{array}{c}\text { Distance } \\
\text { measured }\end{array}$ & $\begin{array}{c}\text { Log (distance } \\
\text { measured) }\end{array}$ \\
\hline & -0.0034 & -0.128 & -0.0365 & -0.169 & -0.0082 \\
Number of & $(0.0165)$ & $(0.536)$ & $\begin{array}{c}(0.0881) \\
7,547\end{array}$ & $\begin{array}{c}(0.243) \\
7,547\end{array}$ & $\begin{array}{c}(0.0543) \\
\text { observations }\end{array}$ \\
7,152 & 7,547 & 7,255 \\
\hline
\end{tabular}

Notes: All columns have the same specification as the main regression but different dependent variables. Standard errors are clustered at the TAZ level. $*, * *, * * *$ indicate $10 \%, 5 \%$ and $1 \%$ significance level, respectively.

(2) through (5). This indicates that commuters did not travel farther to work when rail transit accessibility was improved.

\section{Conclusion}

In this paper, the rapid rollout of new subway lines in urban Beijing is used to test whether the improvement of subway accessibility diverted commuters toward the subway, and from which modes travel was diverted. The main methodology is a DID method which compares changes in the travel behaviors of commuters who reside in the areas with rail accessibility improvement to those who did not experience such improvement. To solve the potential estimation bias posed by the fact that rail expansion may affect commuters residing in areas without rail accessibility improvement through congestion alleviation, due to less driving by the commuters who experienced the subway improvement, the intensity of spillover from the treated is measured and the cross-area externality is estimated as well.

The results indicate that the new subway lines increased the percentage distance traveled by subway by 107 per cent, and decreased the percentage distance traveled by autos on average by 16 per cent in the treated areas relative to the untreated areas. The percentage distance traveled by buses decreased by 7 per cent and is not statistically significant. Along with the increase in subway usage, walking and bicycling distance increased by 10 per cent. The results also show that commuters residing in areas closer to subway stations, rather than those in areas which experienced greater improvement in rail accessibility, were more likely to divert toward the subway; new subway lines built in areas with less road coverage but more bus stops diverted more commuters to the subway; and auto owners and commuters with higher income were less likely to switch from auto use toward subway use. Furthermore, it is found that neither trip length nor number of trips increased with rail expansion. As for the cross-area externality, the spillover effects are found to be small and not statistically significant. This implies that the congestion alleviation effects were not large enough, within the areas and time span of the study, to affect 
the travel behaviors of the commuters residing in areas which did not experience rail accessibility improvements.

Now let us find out what the 16 per cent decrease in auto usage (auto usage decreased from 0.30 of the distance traveled in a trip to 0.25 ) means in economic terms. Many studies have shown that automobile exhaust substantially harms public health. Particulate matter, one of the main pollutants from diesel automobiles, is linked to cardiopulmonary diseases, respiratory infections, lung cancers and infant mortality; other automobile emissions, such as carbon monoxide and nitrogen oxides, are also linked to infant mortality and childhood asthma (Chay and Greenstone, 2003; EPA, 2004; Neidell, 2004; Currie and Neidell, 2005). The externalities caused by auto use also include greenhouse gas emissions, congestion, traffic accidents, noise, and so on. Parry and Small (2009) estimated the externality cost of driving for several large cities over the world, and found that the cost varies from US\$0.46 per mile for Washington, DC to US\$2.42 per mile for London. Although the value of time and value of statistical life are possibly lower in urban Beijing than in Washington, DC because of the lower average wage, the cost of air pollution is not necessarily lower, given the higher population density in urban Beijing. ${ }^{9}$ So this cost range is adopted for the following calculation.

The average work trip distance in the sample is $8 \mathrm{~km}$, and therefore about $0.4 \mathrm{~km}$ is diverted from autos per trip. When the 2015 Plan is completed, all the residents in urban Beijing (11.7 million in 2010) will be within walking distance of at least one subway station. Supposing that two-thirds of them make one round trip per day for work (based on the sample statistics), the total distance saved in auto usage will be 6.27 million $\mathrm{km}$ per day. Therefore, the cost saved by diverting commuters from autos will be US\$1.80m to US\$9.49m per day. Assuming that there are 250 week days per year, US\$0.45bn-US\$2.37bn will be saved in the first year of completion of the 2015 Plan. Regardless of the precise numbers used to interpret the magnitude of the air quality and congestion alleviation benefits, the calculation indicates that the effects of rail transit infrastructure are economically substantial.

Notice that the 16 per cent decrease in auto usage is neither a guarantee nor an upper bound of the effect of rail expansion, because, as shown in this paper, the impacts of rail expansion on mode usage depend on the distance of a new subway station to commuters' residences, the road coverage and bus systems of the areas where the subway stations are built, and the income and auto ownership of the commuters in those areas. A subway line with stations close to residential places in areas with limited road coverage and undeveloped bus services, or in areas where the residents have

9 The population density was 8,500 people per $\mathrm{km}^{2}$ in urban Beijing in 2010. The area of urban Beijing (the eight administrative districts at the center of Beijing, as shown in figure 2) is $1,381 \mathrm{~km}^{2}$ and the population in this area was 11.7 million in 2010 (data source: Population Census of Beijing Municipality in 2010). To compare, the population density is 3,400 people per $\mathrm{km}^{2}$ in Washington, DC, and 5,200 people per $\mathrm{km}^{2}$ in London. 
relatively lower income and less auto ownership, is likely to have a large diversion effect on autos.

\section{References}

Allport, R.J. and J.M. Thomson (1990), Study of Mass Rapid Transit in Developing Countries, Wokingham: TRL.

Alpizar, F. and F. Carlsson (2003), 'Policy implications and analysis of the determinants of travel mode choice: an application of choice experiments to metropolitan Costa Rica', Environment and Development Economics 8(4): 603-619.

Asensio, J. (2002), 'Transport mode choice by commuters to Barcelona's CBD', Urban Studies 39(10): 1881-1895.

Baum-Snow, N. and M.E. Kahn (2000), 'The effects of new public projects to expand urban rail transit', Journal of Public Economics 77(2): 241-263.

Ben-Akiva, M. and S.R. Lerman (1974), 'Some estimation results of a simultaneous model of auto ownership and mode choice to work', Transportation 3(4): 357-376.

Ben-Akiva, M. and T. Morikawa (1990), 'Estimation of switching models from revealed preferences and stated intentions', Transportation Research A 24(6): 485-495.

Cervero, R. (1998), The Transit Metropolis: A Global Inquiry, Washington, DC: Island Press.

Chay, K.Y. and M. Greenstone (2003), 'The impact of air pollution on infant mortality: evidence from geographic variation in pollution shocks induced by a recession', Quarterly Journal of Economics 118(3): 1121-1167.

Chen, Y. and A. Whalley (2012), 'Green infrastructure: the effects of urban rail transit on air quality', American Economic Journal: Economic Policy 4(1): 58-97.

Cohen, A.J., H.R. Anderson, B. Ostro, et al. (2004), 'Urban air pollution', in M. Ezzati, A.D. Lopez, A. Rodgers and J.L. Christopher (eds), Comparative Quantification of Health Risks: Global and Regional Burden of Disease Attributable to Selected Major Risk Factors Vol. 2, Geneva: World Health Organization, pp. 1353-1434.

Currie, J. and M. Neidell (2005), 'Air pollution and infant health: what can we learn from California's recent experience?', Quarterly Journal of Economics 120(3): 1003-1030.

EPA (2004), 'Air quality criteria for particulate matter', EPA/600/P-99/002aF (October), Washington, DC: Environmental Protection Agency.

Gaudry, M. (1975), 'An aggregate time-series analysis of urban transit demand: the Montreal case', Transportation Research 9(4): 249-258.

Gómez-Ibáñez, J.A. (1996), ‘Big-city transit ridership, deficits, and politics: avoiding reality in Boston', Journal of the American Planning Association 62(1): 30-50.

Gordon, P. and R. Willson (1984), 'The determinants of light-rail transit demand - an international cross-sectional comparison', Transportation Research Part A: General 18(2): 135-140.

Greene, D.L. (1992), 'Vehicle use and fuel economy: how big is the rebound effect?', Energy Journal 13(1): 117-143.

Hensher, D.A. and M. Bradley (1993), 'Using stated response data to enrich revealed preference discrete choice models', Marketing Letters 4(2): 139-151.

Hensher, D.A. and J.M. Rose (2007), 'Development of commuter and non-commuter mode choice models for the assessment of new public transport infrastructure projects: a case study', Transportation Research Part A: Policy and Practice 41(5): 428-443.

Imbens, G.W. and J.M. Wooldridge (2009), 'Recent developments in the econometrics of program evaluation', Journal of Economic Literature 47(1): 5-86. 
Kain, J.F. (1968), 'Housing segregation, negro employment, and metropolitan decentralization', Quarterly Journal of Economics 82(2): 175-197.

Kain, J.F. (1990), 'Deception in Dallas: strategic misrepresentation in rail transit promotion and evaluation', Journal of the American Planning Association 56(2): 184-196.

Kain, J.F. (1992), 'The use of straw men in the economic evaluation of rail transport projects', American Economic Review 82(2): 487-493.

Kain, J.F. (1997), 'Cost-effective alternatives to Atlanta's rail rapid transit system', Journal of Transportation Economics and Policy 31(1): 25-49.

Kain, J.F. and Z. Liu (1994), 'Efficiency and locational consequences of government transport policies and spending in Chile', in E.L Glaeser and J.R. Meyer (eds), Chile: Political Economy of Urban Development, Cambridge, MA: Harvard University Press, pp. 105-195.

Kenworthy, J. and F. Laube (2001), The Millennium Cities Database for Sustainable Transport, Brussels: UITP and Perth: ISTP.

Liu, G. (2007), 'A behavioral model of work-trip mode choice in Shanghai', China Economic Review 18(4): 456-476.

McFadden, D. (1974), 'The measurement of urban travel demand', Journal of Public Economics 3: 303-328.

McFadden, D., A.P. Talvitie, and associates (1977), 'Demand model estimation and validation', Urban Travel Demand Forecasting Project, Final Report, Volume V, Berkeley, CA: Institute of Transportation Studies, University of California.

Neidell, M.J. (2004), 'Air pollution, health, and socio-economic status: the effect of outdoor air quality on childhood asthma', Journal of Health Economics 23(6): 1209-1236.

Parry, I. and K. Small (2009), 'Should urban transit subsidies be reduced?', American Economic Review 99(3): 700-724.

Petitte, R.A. (2001), 'Fare variable construction and rail transit ridership elasticities: case study of the Washington, DC, metrorail system', Transportation Research Record: Journal of the Transportation Research Board 1753(1): 102-110.

Pickrell, D.H. (1992), 'A desire named streetcar: fantasy and fact in rail transit planning', Journal of the American Planning Association 58(2): 158-176.

Train, K. (1978), 'A validation test of a disaggregate mode choice model', Transportation Research 12(3): 167-174.

Train, K. (1980), 'A structured logit model of auto ownership and mode choice', Review of Economic Studies 47(2): 357-370.

Train, K. (2009), Discrete Choice Methods With Simulation, 2nd edn, Cambridge: Cambridge University Press.

Vickrey, W.S. (1969), 'Congestion theory and transportation investment', American Economic Review 59(2): 251-260.

Wardman, M. (1997), 'Inter-urban rail demand, elasticities and competition in Great Britain: evidence from direct demand models', Transportation Research Part E: Logistics and Transportation Review 33(1): 15-28.

Winston, C. and C. Shirley (1998), Alternate Route: Toward Efficient Urban Transportation, Washington, DC: Brookings Institution Press.

Yang, J., S. Chen, P. Qin, and F. Lu (2015), 'The effects of subway expansion on traffic conditions: evidence from Beijing', EfD Discussion Paper No. 15-22, August, Environment for Development Initiative. 


\section{Appendix A: Full list of the main results}

Table A1. Effect of subway expansion on mode usage

\begin{tabular}{|c|c|c|c|c|}
\hline & \multicolumn{4}{|c|}{$\begin{array}{l}\text { Dep. variable: percentage distance traveled by a mode } \\
\quad(=\text { distance by a mode/trip distance })\end{array}$} \\
\hline & (1) & (2) & (3) & (4) \\
\hline & Subway & Auto & Bus & $\begin{array}{l}\text { Walking and } \\
\text { bicycling }\end{array}$ \\
\hline Treatment & $\begin{array}{l}0.0273^{* * *} \\
(0.0094)\end{array}$ & $\begin{array}{c}-0.0489^{* *} \\
(0.0223)\end{array}$ & $\begin{array}{r}-0.0189 \\
(0.0261)\end{array}$ & $\begin{array}{c}0.0406^{*} \\
(0.0217)\end{array}$ \\
\hline $\begin{array}{l}\text { Number of trips } \\
\text { from the treated }\end{array}$ & $\begin{array}{c}-0.00099 \\
(0.0027)\end{array}$ & $\begin{array}{c}-0.0086 \\
(0.0102)\end{array}$ & $\begin{array}{c}0.0065 \\
(0.0077)\end{array}$ & $\begin{array}{c}0.0031 \\
(0.0105)\end{array}$ \\
\hline $\begin{array}{l}\text { Number of trips into } \\
\text { a TAZ }\end{array}$ & $\begin{array}{l}-0.00399^{* *} \\
(0.0017)\end{array}$ & $\begin{array}{c}-0.0057^{* *} \\
(0.0027)\end{array}$ & $\begin{array}{c}-0.0046 \\
(0.0038)\end{array}$ & $\begin{array}{l}0.0143^{* * * *} \\
(0.0035)\end{array}$ \\
\hline Auto ownership & $\begin{array}{l}-0.0141^{* *} \\
(0.006)\end{array}$ & $\begin{array}{l}0.166^{* * *} \\
(0.0128)\end{array}$ & $\begin{array}{c}-0.0688^{* * *} \\
(0.0161)\end{array}$ & $\begin{array}{c}-0.0834^{* * *} \\
(0.0171)\end{array}$ \\
\hline Driver's license & $\begin{array}{c}0.0115 \\
(0.0103)\end{array}$ & $\begin{array}{l}0.138^{* * *} \\
(0.0145)\end{array}$ & $\begin{array}{c}-0.0395^{* *} \\
(0.0183)\end{array}$ & $\begin{array}{c}-0.110^{* * *} \\
(0.0170)\end{array}$ \\
\hline $\begin{array}{l}\text { Auto ownership } \times \\
\text { driver's license }\end{array}$ & $\begin{array}{c}-0.0356^{* * *} \\
(0.0111)\end{array}$ & $\begin{array}{l}0.301^{* * *} \\
(0.0219)\end{array}$ & $\begin{array}{c}-0.127^{* * *} \\
(0.0212)\end{array}$ & $\begin{array}{c}-0.139^{* * *} \\
(0.0225)\end{array}$ \\
\hline Income & $\begin{array}{r}0.0041^{*} \\
(0.0023)\end{array}$ & $\begin{array}{l}0.0088^{*} \\
(0.0046)\end{array}$ & $\begin{array}{c}0.0057 \\
(0.0047)\end{array}$ & $\begin{array}{l}-0.0186^{* * *} \\
(0.0046)\end{array}$ \\
\hline Male & $\begin{array}{c}-0.0119^{* *} \\
(0.0056)\end{array}$ & $\begin{array}{l}0.0877^{* * *} \\
(0.0118)\end{array}$ & $\begin{array}{c}-0.0566^{* * *} \\
(0.0124)\end{array}$ & $\begin{array}{c}-0.0192 \\
(0.0131)\end{array}$ \\
\hline Age & $\begin{array}{l}-0.00160^{* * *} \\
(0.0003)\end{array}$ & $\begin{array}{c}-0.0003 \\
(0.0005)\end{array}$ & $\begin{array}{l}-0.0027^{* * *} \\
(0.0005)\end{array}$ & $\begin{array}{l}0.0046^{* * *} \\
(0.0006)\end{array}$ \\
\hline Constant & $\begin{array}{r}0.154^{* *} \\
(0.0759)\end{array}$ & $\begin{array}{c}0.0339 \\
(0.107)\end{array}$ & $\begin{array}{l}0.497^{* *} \\
(0.201)\end{array}$ & $\begin{array}{l}0.314^{* *} \\
(0.156)\end{array}$ \\
\hline $\begin{array}{l}\text { Number of } \\
\text { observations }\end{array}$ & 7,547 & 7,547 & 7,547 & 7,547 \\
\hline
\end{tabular}

Notes: Full results of the main regressions. Standard errors are clustered at the TAZ level. ${ }^{*}, * *, * *$ indicate $10 \%, 5 \%$ and $1 \%$ significance level, respectively. 
Appendix B: Measuring treatment effect heterogeneity in percentage change

Table B1. Measuring treatment effect heterogeneity in percentage change

\begin{tabular}{|c|c|c|c|c|c|}
\hline $\begin{array}{l}\text { Panel A. auto ownership } \\
\text { and driver's license }\end{array}$ & & nple & Effect & $\begin{array}{l}\text { Percentage } \\
\text { distance }\end{array}$ & $\%$ change \\
\hline Subway & & & & & \\
\hline No auto & 289 & $31.6 \%$ & 0.0186 & 0.0208 & $89.3 \% * * *$ \\
\hline Auto owner & 288 & $31.4 \%$ & 0.0201 & 0.1506 & $13.4 \% * *$ \\
\hline Auto & & & & & \\
\hline No auto & 289 & $31.6 \%$ & -0.0338 & 0.0251 & $-134.8 \% * *$ \\
\hline Auto owner & 288 & $31.4 \%$ & -0.0394 & 0.6971 & $-5.7 \% * *$ \\
\hline Bus & & & & & \\
\hline No auto & 289 & $31.6 \%$ & -0.0195 & 0.3900 & $-5.0 \%$ \\
\hline Auto owner & 288 & $31.4 \%$ & -0.0181 & 0.0941 & $-19.3 \%$ \\
\hline Walking and bicycling & & & & & \\
\hline No auto & 289 & $31.6 \%$ & 0.0347 & 0.564066 & $6.2 \% *$ \\
\hline Auto owner & 288 & $31.4 \%$ & 0.0374 & 0.193745 & $19.3 \% * *$ \\
\hline $\begin{array}{l}\text { Panel B. } \\
\text { income levels }\end{array}$ & & nple & Effect & $\begin{array}{l}\text { Percentage } \\
\text { distance }\end{array}$ & $\%$ change \\
\hline Subway & & & & & \\
\hline Income level 2 & 142 & $15.5 \%$ & 0.0216 & 0.0114 & $189.8 \% *$ \\
\hline Income level 3 & 203 & $22.2 \%$ & 0.0231 & 0.0180 & $128.6 \%{ }^{* *}$ \\
\hline Income level 4 & 324 & $35.4 \%$ & 0.0246 & 0.0349 & $70.4 \% * *$ \\
\hline Income level 5 & 181 & $19.8 \%$ & 0.0261 & 0.0289 & $90.2 \% *$ \\
\hline Auto & & & & & \\
\hline Income level 2 & 142 & $15.5 \%$ & -0.0450 & 0.1928 & $-23.4 \%$ \\
\hline Income level 3 & 203 & $22.2 \%$ & -0.0506 & 0.2518 & $-20.1 \% * *$ \\
\hline Income level 4 & 324 & $35.4 \%$ & -0.0562 & 0.3061 & $-18.4 \% * *$ \\
\hline Income level 5 & 181 & $19.8 \%$ & -0.0619 & 0.4065 & $-15.2 \% * *$ \\
\hline Bus & & & & & \\
\hline Income level 2 & 142 & $15.5 \%$ & -0.0167 & 0.2244 & $-7.5 \%$ \\
\hline Income level 3 & 203 & $22.2 \%$ & -0.0153 & 0.2861 & $-5.4 \%$ \\
\hline Income level 4 & 324 & $35.4 \%$ & -0.0139 & 0.2849 & $-4.9 \%$ \\
\hline Income level 5 & 181 & $19.8 \%$ & -0.0126 & 0.2266 & $-5.5 \%$ \\
\hline Walking and bicycling & & & & & \\
\hline Income level 2 & 142 & $15.5 \%$ & 0.0401 & 0.5714 & $7.0 \%$ \\
\hline Income level 3 & 203 & $22.2 \%$ & 0.0429 & 0.4440 & $9.7 \%$ \\
\hline Income level 4 & 324 & $35.4 \%$ & 0.0456 & 0.3740 & $12.2 \% *$ \\
\hline Income level 5 & 181 & $19.8 \%$ & 0.0483 & 0.3380 & $14.3 \%$ \\
\hline
\end{tabular}

